\title{
Prediction of Transformer Insulation Life with an Effect of Environmental Variables
}

\author{
M. Srinivasan \\ Associate Professor, \\ Velalar College of Engineering and Technology, \\ Erode -638012, Tamilnadu, INDIA.
}

\author{
A. Krishnan, PhD. \\ Dean, \\ K S Rangasamy College of Technology, \\ Tiruchengode, Tamilnadu, INDIA.
}

\begin{abstract}
The Hot Spot Temperature (HST) value depends on the ambient temperature, the rise in the top oil temperature (TOT) over the ambient temperature, and the rise in the winding HST over the top oil temperature. In this paper a new semi-physical model comprising of the environmental variables for the estimation of HST and loss of insulation life in transformer is proposed. The winding hot-spot temperature can be calculated as a function of the top-oil temperature that can be estimated using the transformer loading data, top oil temperature lagged regressor value, ambient temperature, wind velocity and solar heat radiation effect. The estimated HST is compared with measured data of a power transformer in operation. The proposed model has been validated using real data gathered from a 100 MVA power transformer.
\end{abstract}

\section{General Terms}

Power Transformer, Ambient Temperature.

\section{Keywords}

Hot Spot Temperature - Top Oil Temperature - Insulation Life - Semiphysical model.

\section{INTRODUCTION}

Power transformers are the main components and constitute a large portion of capital investment. When a power transformer fails, an adverse effect occurs in the operation of transmission and distribution networks resulting in increase of the power system operation cost and decrease of reliability in electricity delivery.

A prospective the transformer designer employs detailed electrical models to develop reliable and cost effective transformer insulation. Transformer aging can be evaluated using the HST. The increase in TOT and thereby increase in HST has the effect of reducing insulation life [1],[2],[3],[4]. Abnormal conditions, such as overloading, supplying nonsinusoidal loads or exposure to higher ambient temperature than normal, can accelerate transformer aging and accordingly accelerate the time to end of life. The increase in TOT and HST accelerates the end of the transformer lifetime. The average lifetime of oil-immersed transformers based on the lifetime of the solid insulation is well defined in [5], in which the average lifetimes based on different end of life criteria are summarized. The load on a transformer cannot be increased indefinitely without causing premature aging of transformer's insulation. Aging or deterioration of insulation is a timefunction of temperature, moisture content, and oxygen content. The moisture and oxygen contributions to insulation deterioration can be minimized with modern oil preservation systems, leaving insulation temperature as the primary parameter. The primary contributor to insulation temperature is the heat generated by load losses. Since the deterioration in the insulation is related to the insulation temperature and the temperature distribution due to load losses is not uniform in the windings in most cases, it is reasonable to believe that the greatest deterioration to the insulation will happen at the part of the winding operating under the highest temperature condition [6]. Therefore, in aging studies it is usual to consider the aging effects caused by the HST. The variation of power transformer loading beyond nameplate rating in both normal and emergency cases increases temperature inside the transformer tank and may causes the rapid thermal deterioration of the insulation [7]. This is a cause of transformer failure. In order to make the power transformers in terminal stations operate at their full capacity without failures due to temperature increase at the same time, a careful study of their entire thermal behavior is needed. The standard normal lifetime for oil-immersed power transformer for a continuous HST of $110{ }^{\circ} \mathrm{C}$ based on [1] and other IEEE standards.

There are two approaches to deal with HST: to measure it or to calculate it [8]. Measuring the HST imposes unwanted costs to the system. For this reason, several models for prediction of HST have been presented in the literature [9]. Since the thermal phenomena are quite complex, it is not easy to consider all the details in the thermal model precisely. There are some simplified thermal models in the appropriate standards such as IEEE which have limited accuracy. The commonly used model is described in clause 7 in the IEEE loading guide [1]. The top oil rise equation of clause 7 of the IEEE guide is modified to allow for continuously varying ambient temperature [10],[11],[12]. An alternative method is suggested in Annexure G. The method requires the use of bottom oil rise over ambient at rated conditions. The duct oil temperature is introduced which may be higher than the top oil temperature under certain conditions [3]. Also this model requires more test parameters for calculating HST.

The prediction of HST compared with measured HST, the error is most likely due to insufficient driving variable data rather than an inaccurate or insufficient model [13]. Also, several attempts needed to optimize the parameters shown the paper [14], and it is report that on the results of several in attempts to improve the model used for predicting transformer TOT and HST. The result of this research lends additional support to the hypothesis that accurate prediction of transformer HST is due to noise in the input data and the absence of measurements for significant driving variables.

In this paper, introduce the additional environmental variation factors such as wind velocity and solar radiation. It is assess the loss of life of proposed model. This paper is organized as follows. Section 2 reviews the thermal model for power 
transformer. Section 3 discusses the transformer description, which is the collection of data and design values used to construct the different models. Section 4 discusses the assessing of transformer insulation life characteristics. Section 5 discusses the transformer loss of life evaluation. Section 6 discusses the results and discussions and section 7 discusses the conclusions.

\section{THERMAL MODEL FOR POWER TRANSFORMER}

When a transformer is energized and loaded at ambient temperature $\left(\theta_{\mathrm{A}}\right)$, dissipation caused by core losses, winding losses, stray losses in the tank and metal support structures are sources of heat which cause the transformer oil and winding temperature rise. The transformer oil is cooled by the radiator assembly and flows to the bottom of the cooling ducts to reach bottom oil temperature $\left(\theta_{\mathrm{bo}}\right)$. The transformer oil flows vertically upward the winding ducts and exits the winding ducts at the top winding duct oil temperature. The transformer oil enters the radiators at the top oil temperature in the main tank $\left(\theta_{\text {top }}\right)[3]$.

IEEE Loading Guide [1] has been used to calculate hotspot temperature. The bottom and top oil temperature are measured during temperature-rise test in manufacturer's plant. In the same process the average oil temperature rise is calculated, and the average winding temperature is obtained by resistance variation [3]. These thermal parameters use to construct the thermal model of oil-immersed transformer, as shown in Fig.1.

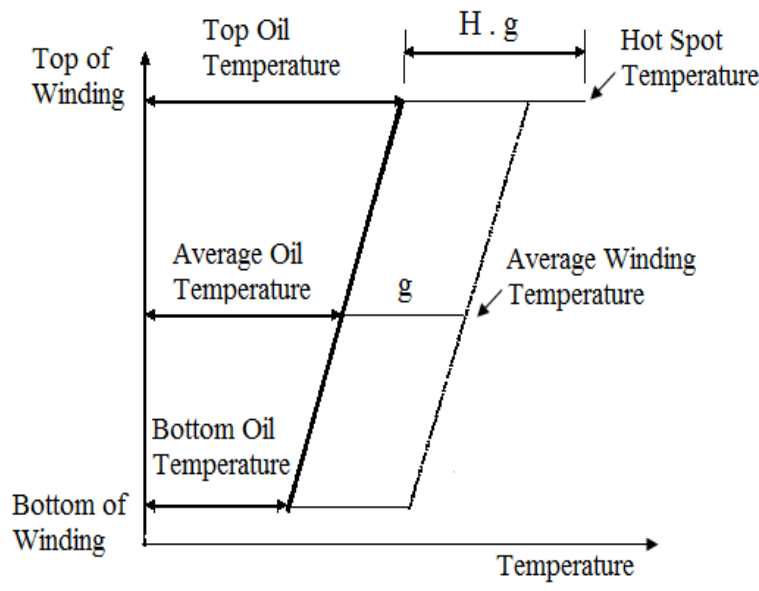

Fig. 1: Transformer Thermal Diagram

In this model, the hot-spot temperature is the sum of ambient temperature, top oil temperature rise $\left(\Delta \theta_{\text {top }}\right)$, and hot-spot to top oil temperature gradient $\left(\Delta \theta_{H}=\mathrm{H} . \mathrm{g}\right)$, where $\mathrm{H}$ is hot-spot factor and ' $\mathrm{g}$ ' is thermal gradient between winding and oil average temperatures.

This diagram is based on the following assumptions:

- The change in the oil temperature inside and along the winding is linearly increasing from bottom to top.

- The increase in the winding temperature from bottom to top is linear with a constant temperature difference ' $\mathrm{g}$ '.

- At the top of the winding HST is higher than the average temperature rise of the winding. The difference in the temperature between the hot spot and the oil at the top of the winding is defined as H.g, where $\mathrm{H}$ is a hot spot factor. It may be vary from 1.1 to 1.5 , depending on short circuit impedance, winding design and transformer size.

\subsection{Top Oil Equation}

The traditional IEEE top-oil-rise (Clause 7) model [1], is governed by the differential equation:

$$
T_{0} \frac{d \theta_{0}}{d t}=-\theta_{0}+\theta_{u}
$$

Solution of above differential equation:

$$
\theta_{0}=\left(\theta_{u}-\theta_{i}\right)\left(1-e^{-t / T_{0}}\right)+\theta_{i}
$$

Where

$$
\theta_{u}=\theta_{f l}\left(\frac{K^{2} R+1}{R+1}\right)^{n}
$$

$T_{0}=\frac{C \theta_{f l}}{P_{f l}}$

and

$\theta_{o}$ - top-oil rise over ambient temperature $\left({ }^{\circ} \mathrm{C}\right)$

$\theta_{u}$ - ultimate top-oil rise for load $\mathrm{L}\left({ }^{\circ} \mathrm{C}\right)$;

$\theta_{i}$ - initial top-oil rise for $\mathrm{t}=0\left({ }^{\circ} \mathrm{C}\right)$;

$\theta_{f l}$ - top-oil rise over ambient temperature at rated load $\left({ }^{\circ} \mathrm{C}\right)$

$T_{o}$ - time constant (h);

$C$ - thermal capacity $\left(\mathrm{MWh} /{ }^{\circ} \mathrm{C}\right)$;

$P_{f l}-$ total loss at rated load (MW)

$n$ - oil exponent

$K$ - ratio of load $\mathrm{L}$ to rated load;

$R$ - ratio of load loss to no-load loss at rated load.

However, this fundamental model has the limitation that it does not accurately account for the effect of variations in ambient temperature, and therefore is not applicable for an online monitoring system. Lesieutre.B.C [15] has proposed a modified top-oil temperature model developed from the IEEE top-oil rise temperature model by considering the ambient temperature at the first-order characterization. Moreover, in place of mention in top-oil rise over ambient temperature, the final temperature state is considered in the model. To correct this for ambient temperature variation, recognize that the time-rate-of-change in top-oil temperature is driven by the difference between existing top-oil temperature and ultimate top-oil temperature $\left(\theta_{\mathrm{u}}+\theta_{\mathrm{amb}}\right)$ :

$$
T_{0} \frac{d \theta_{t o p}}{d t}=-\theta_{t o p}+\theta_{u}+\theta_{\text {amb }}
$$

Where

$\theta_{a m b}$ - ambient air temperature $\left({ }^{\circ} \mathrm{C}\right)$;

Discretizing this model using the backward Euler rule because of its stability properties, rearranging the above equation yields,

$$
\begin{aligned}
\theta_{\text {top }}(k) & =\frac{T_{0}}{T_{0}+\Delta t} \theta_{0}[k-1]+ \\
& \frac{\Delta t \theta_{f l} R}{\left(T_{0}+\Delta t\right)(R+1)}\left(\frac{I[k]}{I_{\text {rated }}}\right)^{2 n} \frac{\Delta t \theta_{f l}}{\left(T_{0}+\Delta t\right)(R+1)}+\theta_{\text {amb }}(t)
\end{aligned}
$$

Where

$$
\begin{aligned}
\mathrm{n}= & 0.8 \text { for Oil Natural Air Natural (ONAN) } \\
= & 0.9 \text { for Oil Natural Air Forced (ONAF) or Oil } \\
& \text { Forced Air Forced (OFAF) Non Directed } \\
= & 1.0 \text { for Oil Forced Air Forced Directed } \\
& (\text { OFAFD) }
\end{aligned}
$$

For forced cooling systems using the value $\mathrm{n}=1$, the above model is simplified to, 


$$
\begin{aligned}
\theta_{\text {top }}[k]= & \frac{T_{0}}{T_{0}+\Delta t} \theta_{\text {top }}[k-1]+\frac{\Delta t}{\left(T_{0}+\Delta t\right)} \theta_{\text {amb }}[k]+ \\
& \frac{\Delta t \theta_{f l} R}{\left(T_{0}+\Delta t\right)(R+1)}\left(\frac{I[k]}{I_{\text {rated }}}\right)^{2}+\frac{\Delta t \theta_{f l}}{\left(T_{0}+\Delta t\right)(R+1)}
\end{aligned}
$$

Rewriting the above equation in a discretized form, substituting K's for the constant coefficients,

$$
\theta_{\text {top }}[k]=K_{1} \theta_{\text {top }}[k-1]+\left(1-K_{1}\right) \theta_{\text {amb }}[k]+K_{2} I[k]^{2}+K_{3}
$$

Where $K_{1}-K_{3}$ are complex functions of the respective differential equation coefficients, and is the per-unit transformer current (based on the rated value of the transformer) at time-step index $\mathrm{k}$.

The coefficient (1-k) is replaced by another coefficient $k_{4}$,

$$
\theta_{\text {top }}[k]=K_{1} \theta_{\text {top }}[k-1]+K_{4} \theta_{\text {amb }}[k]+K_{2} I[k]^{2}+K_{3}
$$

The linearized models in (8) and (9) are both physical models; they are based on physical principles.

\subsection{Hot Spot Equation}

It is made several changes to the top-oil model in hopes of improving its performance. This is to be expected since, by adding another coefficient, It is added an extra degree of freedom that the linear optimization routine can use to find a better model. The resulting model is known as a semiphysically based model because it is not entirely based on physical principles.

It is construct the model was to account for solar radiation and wind velocity ref. in [16], [17]. Solar radiation and wind velocity is a significant source of environmental variation factors when transformer placed in outdoor. The equations (10) and (11) are used to predict the HST via top oil temperature rise model.

$$
T_{0} \frac{d \theta_{t o p}}{d t}=-\theta_{\text {top }}+\theta_{u}+\theta_{\text {amb }}+\theta_{R}+\theta_{w x}+\theta_{w y}
$$

Discretizing (10) using the backward Euler discretization rule gives the linear form,

$$
\begin{aligned}
& \theta_{\text {top }}[k]=K_{3} \theta_{\text {top }}[k-1]+K_{2} \theta_{\text {amb }}[k]+K_{1} I[k]^{2} \\
& +K_{4}+K_{5} \mathrm{~S}_{\text {rad }}[k]+K_{6} V_{x}[k]+K_{7} V_{y}[k]
\end{aligned}
$$

Where, coefficients $\mathrm{K}_{1}-\mathrm{K}_{7}$ can be calculated from measured data using standard linear least squares technique, since all of them appear linearly in the model [18], [19].

Using TOT predicted by the model (11), it is to calculate the HST from the following equation:

$$
\theta_{h}=\theta_{\text {top }}+\theta_{h m}\left(\frac{I(k)}{I_{\text {rated }}}\right)^{2 m}
$$

Where $\theta_{\mathrm{hm}}$ is the maximum HST over TOT in the rating load that provided by manufacturer. In this case study $\theta_{\mathrm{hm}}$ is $36^{\circ} \mathrm{C}$. Also, $\mathrm{m}$ is the cooling coefficient and can vary in the range of $0.8-1$. In this study forced cooling system is considered in which $\mathrm{m}$ is 1 .

\section{Transformer Description}

To validate the proposed model, data gathered under various

\begin{tabular}{|c|c|}
\hline Parameter & Value \\
\hline Rating & $100 \mathrm{MVA}$ \\
\hline Rated Voltage & $230 \mathrm{kV}$ \\
\hline LV & $110 \mathrm{kV}$ \\
\hline Rated Line Current & $251.3 \mathrm{~A}$ \\
\hline LV & $525.5 \mathrm{~A}$ \\
\hline Weight of core \& Coil & $74,000 \mathrm{kgs}$. \\
\hline Weight of Tank and Fittings & $35,000 \mathrm{kgs}$. \\
\hline Oil mass & 41,800 kgs. \\
\hline Total Weight & $1,50,800 \mathrm{kgs}$. \\
\hline Volume of Oil & 4,700 lit. \\
\hline Top Oil Temperature Rise & $50^{\circ} \mathrm{C}$ \\
\hline $\begin{array}{l}\text { Hottest Spot Conductor rise over } \\
\text { Top Oil temp. rise at rated load }\end{array}$ & $36^{\circ} \mathrm{C}$ \\
\hline $\begin{array}{l}\text { Ratio of Load loss at rated load to } \\
\text { no-load loss }(\mathrm{R})\end{array}$ & 5.0 \\
\hline Oil time constant (Watt-hour/ ${ }^{\circ} \mathrm{C}$ ) & 3.0 \\
\hline
\end{tabular}
load conditions from a real power transformer (100 MVA and $230 / 110 \mathrm{kV}$ ) which are recorded in the month of may, have been used. In this study, work has been carried out in a power transformer situated at Perundurai, Tamilnadu, with the specifications as shown in Table 1.

Table 1. Rating of Substation Distribution Transformer (SDT)

TOT, Load, and ambient temperature were sampled every 30 minutes for 24 hours. Similarly, wind velocity and solar radiation measured and missed data were received from metrological department. The data were filtered to eliminate bad data and divided into separate data files. The models built in this work use only the highest cooling mode: NOFA or FOFA.

\section{Transformer Insulation Life Characteristics}

Insulation aging is a function of temperature and other environmental factors. Today with modern cooling systems, the effect of solar heat flux can be reduced, but the temperature is a limiting factor that should not exceeded from a predetermined value. Since, in most apparatus, the temperature distribution is not uniform, that part which is operating at the highest temperature will ordinarily undergo the greatest deterioration. Therefore, in aging studies, it is usual to consider the aging effects produced by hottest spot temperature.

\subsection{Aging calculation}

IEEE Loading guide show that insulation life is an exponential function of HST [1]:

$$
\% \text { of Insulation life }=A \cdot e^{\left(\frac{B}{\theta_{h}+273}\right)}
$$

Where $\theta_{\mathrm{h}}$ is the HST $\left({ }^{\circ} \mathrm{C}\right), \mathrm{A}$ and $\mathrm{B}$ are constants that are determined according to insulation material and HST reference defined for normal insulation life. Equation (13) can be used for both distribution and power transformers because both are manufactured using the same cellulose insulation. For instance, suppose HST reference for insulation life to be $110{ }^{\circ} \mathrm{C}$. It means that if the transformer works continuously with this HST, its life will be 1 per unit (life in hour can be determined according to the used insulation). Using above assumptions, equation (13) would be:

$$
\text { Per Unit Life }=9.8 \times 10^{-18} e^{\left(\frac{15000}{\theta_{h}+273}\right)}
$$

Equation (14) yields a value of 1 per unit life for the reference HST of $110^{\circ} \mathrm{C}$ and it is the basis for calculating the aging accelerating factor $\left(\mathrm{F}_{\mathrm{AA}}\right)$. 
The $\mathrm{F}_{\mathrm{AA}}$ is the rate at which a transformer insulation aging is accelerated compared with the aging rate at $110^{\circ} \mathrm{C} . \mathrm{F}_{\mathrm{AA}}$ is given as

Aging Accerlation Factor,

$$
\mathrm{F}_{\mathrm{AA}}=e^{\left(\frac{15000}{383}-\frac{15000}{\theta_{h}+273}\right)}
$$

$\mathrm{F}_{\mathrm{AA}}$ is greater than 1 when the HST is over $110^{\circ} \mathrm{C}$ and less than 1 when the $\mathrm{HST}$ is below $110{ }^{\circ} \mathrm{C}$. Some $\mathrm{F}_{\mathrm{AA}}$ values at different temperatures are presented in Table 2. The conclusion from Table 2 is that the loss of life of transformer insulation is related to the HST exponentially.

The HST is varying according to load and ambient temperature. For this reason, (15) may be used to calculate equivalent aging acceleration factor of the transformer. The equivalent aging acceleration factor at the reference temperature in a given time period for the given temperature cycle is defined as:

$$
F_{E A A}=\frac{\sum_{n=1}^{N} F_{A A, n} \Delta t_{n}}{\sum_{n=1}^{N} \Delta t_{n}}
$$

Where $\mathrm{F}_{\mathrm{EAA}}$, is equivalent aging acceleration factor for the total time period. $N$ is total number of time intervals. $\Delta \mathrm{t}_{\mathrm{n}}$ is $\mathrm{n}^{\text {th }}$ time interval and $F_{E A A, n}$ is aging acceleration factor for the temperature which exists during the time interval $\Delta \mathrm{tn}$.

Table 2. Aging Acceleration Factor at

\begin{tabular}{|c|c|c|c|}
\hline \multicolumn{4}{|c}{ Different HST Values } \\
\hline 70 & 0.0104 & 120 & 2.7089 \\
\hline 80 & 0.0358 & 130 & 6.9842 \\
\hline 90 & 0.1156 & 140 & 17.1995 \\
\hline 100 & 0.3499 & 150 & 40.5890 \\
\hline 110 & 1.0 & 160 & 92.0617 \\
\hline
\end{tabular}

\subsection{Percentage Loss of Life}

The equivalent loss of life in the total time period is determined by multiplying the equivalent aging by the time period ( $\mathrm{t}$ ) in hours. In this case total time period used is 24 hours. Therefore, the equation of percent loss of life equation is as follows [1] :

$$
\% \text { Loss of Life }=\frac{F_{E A A} \times t \times 100}{\text { Normal Insulation Life }}
$$

\section{Transformer Loss of Life Evaluation}

The evaluation based on the climatic parameters included in the TOT and HST calculations. It is to construct four different models using equation (12), according to the inclusion of environmental variables solar radiation heat flux and wind velocity as follows:

Model 1: Derived from Amoda model

Model 2: Proposed Semi-physically based model with solar radiation and wind velocity effects

Using linear regression analysis and least square estimation method estimate the top oil temperature and hot spot temperature by equations (11) and (12). For this linear model, the $\mathrm{X}$ matrix contains measured values of $I^{2}, \theta_{a m b}$, solar radiation $S_{\text {rad }}$, wind velocity components $V_{x}, V_{y}$ and as a lagged regressor, $\theta_{\text {top. }}$ Fig. 2 shows the received heat flux during peak summer at the transformer surfaces. Similarly Fig. 3 shows the received wind velocity during peak summer at the transformer surfaces.

Using equation (13), determine the coefficients, to run the MATLAB programme and perform the multiple linear regression analysis (MLR). One option is the Statistical Toolbox, which allows the user to program with functions. MATLAB programs can also be written with $m$-files. These files are text files created with either functions or script. A function requires an input or output argument. While the function method simplifies writing a program, using script better illustrates the process of obtaining the least squares estimator using matrix commands.

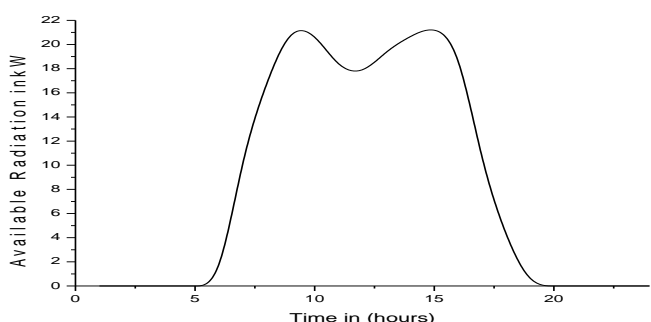

Fig. 2: Plot of heat flux versus time for all the surfaces

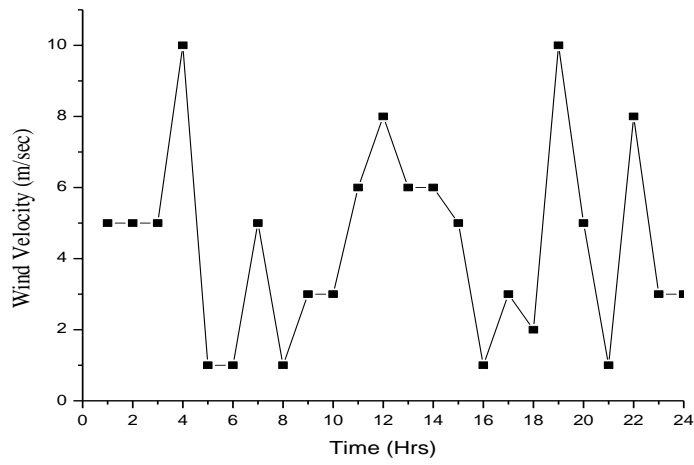

Fig. 3 : Plot of Wind Speed versus time for all the surfaces

\section{Results and Discussions}

\subsection{Load Profile}

Fig. 4 shows the typical load, ambient temperature and hottest spot temperature profile for 24 hours normal load cycle in summer season (mid of may) of a 230/110 kV, 100 MVA substation distribution transformer.

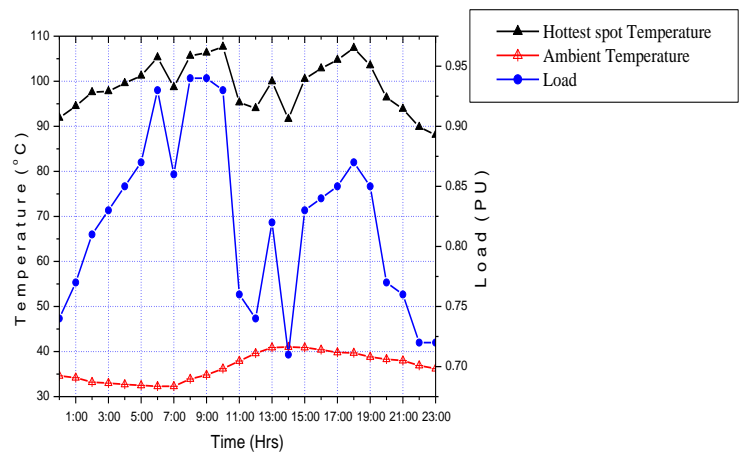

Fig. 4 : Typical Load, Ambient and Hotspot Temperature curve for 24 hrs normal load cycle 
Fig. 5 shows that the estimated results of corresponding aging accerlation factor for normal load cycle. The results obtained using IEEE loss of life equation, at normal load cycle accumulated aging is 8.830 hours of $1,80,000$ hours with the hot spot temperature is not exceed to $110^{\circ} \mathrm{C}$. Fig. 5 shows that the aging acceleration factor increases appropriately due to the load variation. The equivalent aging accerlation factor for normal 24 hours load profile is 0.37

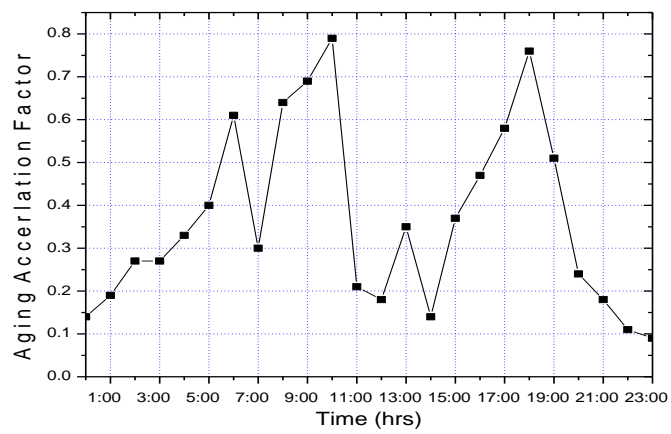

Fig. 5 : Aging Accerlation Factor for 24 hrs Normal load cycle

\subsection{Load Profile for semi physical model}

It is derived from the two models, the changes of load would be greater comparing to thermal changes which result appropriate effect of temperature on the models. It is to investigate the effect of environmental variables and ambient temperature on transformer's insulation life. To do this, first it is to calculate the $\theta_{\text {top }}$ using (11) for the given load and ambient temperature and then with substituting it in (12) then calculate the HST. The results of final predicted proposed HST (model 2) and amoda method (model 1) compared with measured value and results in percentage of error is shown in Fig.6.

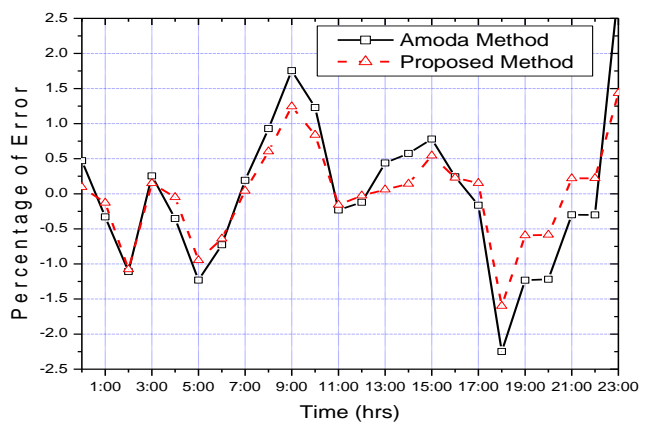

Fig. 6 : Hot Spot Temperature: Error Comparison for normal load profile

Calculation derived from two models cumulative insulation age for normal load profile using equation (15) and the results compared with actual are shown in Fig. 7, also it should use to calculate equivalent aging acceleration factor (Equation (16)).

Accumulation of age for actual (HST Measured using optical fibre measurement) is more compared with two models and model 2 closer than Model 1. The equivalent aging acceleration factor in two cases are added for each hour and divided by the time cycle of total time period ( 24 hours).

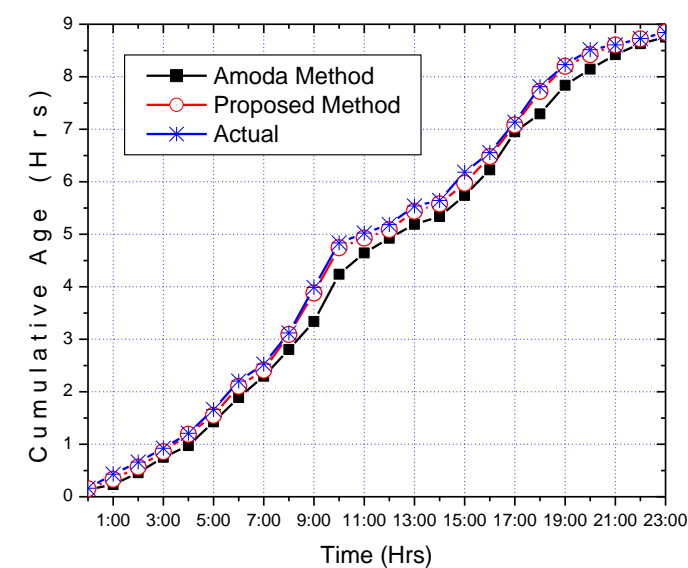

Fig. 7 : Cumulative insulation age Comparison for normal load profile

\subsection{Environmental variable effects}

Fig. 6 and Fig. 7 shows that the HST and cumulative age calculations are made for semi physical model with normal load profile. The loss of life (using Equation (17)) in percentage for 24 hours load profile is shown in Table 3 . In normal load profile model 2 shows better result which is closer to the actual HST.

Table 3. Percentage Loss of life

\begin{tabular}{|c|c|c|}
\hline \multicolumn{3}{|c|}{$\%$ Loss of Life } \\
\hline Model 1 & Model 2 & Actual \\
\hline 0.004914 & 0.00493 & 0.00495 \\
\hline
\end{tabular}

In order to show the performance of the model as well as its precision and accuracy in HST modeling, 24 hours data's are used to predict TOT in all ranges. Fig. 3 shows that addition of wind velocity and solar radiation of model 2 . It is able to produce better result. The error between measured and predicted values is minimum.

\section{CONCLUSION}

In this paper an improved model for the estimation of TOT in transformers was proposed. The authors have used two models to attempt to accurately predict transformer temperature and loss of life for normal load cycle. The actual 24 hours data's of ambient temperature, solar heat flux, and wind velocity in summer season are the base parameters for proposed method. The proposed model predicts the insulation life which is closer to the actual and it is concluded that the end period is eight months earlier than the actual due to not taking in to account of environmental factors. The preferred model for predicting HST is the linear semi-physically based model because it permits the use of simple and robust linear regression techniques. In this method, It is expected the addition of solar radiation and wind velocity to significantly reduce the gap between actual and predicted. In this paper was shown that model 2 is a good model. Using the proposed semi physical model, the effect of ambient temperature and environmental variables on transformer insulation aging was investigated. Although in this study the proposed model was used to study the effect of environmental variables on insulation life, it is an exact model and used to predict the percentage loss of life the transformer. 


\section{REFERENCES}

[1] IEEE Standard, C57.91-1995, IEEE Guide for Loading Mineral Oil Immersed Transformer.

[2] G.Swift, T. S. Molinski, and W. Lehn, A fundamental approach to transformer thermal modeling-Part I: Theory and equivalent circuit, IEEE Trans. Power Delivery, Vol. 16, No. 2, p.171-175,2001.

[3] Susa.D, Lehtonen.M, and Nordman.H, Dynamic thermal modelling of power transformers, IEEE Trans. Power Delivery. 197-204, 2005.

[4] Jauregui-Rivera.L and Tylavsky.D.J, Acceptability of four transformer top-oil thermal models-Part 1: Defining metrics, IEEE Trans. Power Delivery, Vol. 23, No.2, P.860-865, 2008.

[5] Jauregui-Rivera.L and Tylavsky.D.J. Acceptability of four transformer top-oil thermal models-Part II: Comparing metrics, IEEE Trans. Power Delivery, Vol. 23, No.2, p.866-872, 2008.

[6] Mohamed Yazdani-asrami, Mohammed Mirzaie, A.S.Akmal, S.A.Gholamian, Life estimation of distribution transformers under non-linear loads using calculated loss by 2D FEM, J. of Electrical systems, Vol.7, No.1,p. 12-24, 2011

[7] Saha T.K., Purkait P, Investigations of Temperature Effects on the Dielectric Response Measurements of Transformer Oil-Paper Insulation System. IEEE Transactions on Power Delivery, Vol. 23, No. 1, p.252260, 2008.

[8] Amoda.O. A, Tylavsky.D.J, McCulla. G. A, and Knuth.W.A, Evaluation of hottest-spot temperature models using field measured transformer data. International journal of Emerging Electric power systems, Vol. 12, issue 5, art 2, 2011.

[9] Amoda.O. A, Tylavsky.D.J. McCulla. G. A, and Knuth.W.A, Acceptability of Three Transformer HottestSpot Temperature Models. IEEE Trans. On Power Delivery, Vol. 27, No. 1, p.13-22, 2012
[10] Abbas Shiri, Ahmad Gholami, Abbas Shoulaie, Investigation of the ambient temperature effects on transformer's insulation life, Electrical Engineering, (2011) 93, p.193-197, DOI:10.1007/s00202-011-0202-x.

[11] Tylavsky.D. J, He.Q, McCulla.G. A, and. Hunt. J.R, Sources of Error in Substation Distribution-Transformer Dynamic Thermal Modeling. IEEE Trans. on Power Delivery, Vol.15, No.1, p.178-185, 2000.

[12] S. Tojo, Proposition of individual loading guide for power transformers, IEEE Trans. On Power Delivery, Vol. 21, No. 3, p. 1383-1389, Jul. 2006.

[13] Tylavsky. D. J , Mao. X, McCulla. G. A. Transformer Thermal Modeling: Improving Reliability Using Data Quality Control. IEEE Trans. On Power Delivery. Vol. 21,.No. 3, July 2006

[14] Mohammad Ali Taghikhani, Power Transformer Top Oil Temperature Estimation with GA and PSO Methods, Energy and Power Engineering, Vol.4, 41-46, 2012.

[15] Lesieutre. B. C, Hagman.W. H, and Kirtley Jr. J. L, An improved transformer top oil temperature model for use in an on-line monitoring and diagnostic system, IEEE Trans. On Power Delivery, Vol.12, No.1, p. 249-256, 1997.

[16] Kreith.F and Kreider J. F, Principles of Solar Engineering”, Washington, DC: Hemisphere. 1978

[17] Tony Burton, David Sharpe, Nick Jenkins, Ervin Bossanyi, Wind Energy: Hand book. John wiley \& Sons, Ltd., England, 2001.

[18] D. C. Montgomery, E. A. Peck, and G. G. Vining, Introduction to Linear Regression Analysis, 3rd ed. New York: Wiley, 2001.

[19] M.Srinivasan, A.Krishnan, Hot Resistance Estimation for Dry Type Transformer Using Multiple Variable Regression, Multiple Polynomial Regression and Soft Computing Techniques, American journal of applied sciences, Vol.9, No.2, p. 231-237, 2012 